\title{
Socio-demographic correlates of first dose of measles (MCV1) vaccination coverage in India
}

\author{
Basant Kumar Panda ${ }^{1}$, Suyash Mishra ${ }^{1 *}$ and Niyi Awofeso ${ }^{2}$
}

\begin{abstract}
Background: Between 2010 and 2018, measles-related mortality had halved in India mainly with effective measles vaccination campaigns and widespread coverage across the states and population subgroups. Despite the commendable vaccination coverage, 2.9 million children in India missed the first dose of measles vaccine (MCV1) in 2017, and many of those vaccinated were not vaccinated at the recommended age (i.e. between 9 and 12 months). This study analyzed pattern and correlates of MCV1 coverage and MCV1 administration at recommended age among children aged 12-23 months in India.

Methods: We used the official data from the recent round of National Family Health Survey (NFHS-4), a nationally representative cross-sectional household survey in India conducted in 2015-16. Descriptive statistics and logistic regression analysis were applied to ascertain the influence of specified socio-demographic variables affecting measles vaccination coverage in India.
\end{abstract}

Results: The study revealed the distinct variations in coverage of MCV1 between the districts of India. There were also major challenges with age recommended vaccination, with about 15\% of eligible children not vaccinated within the recommended age range, attributable to several socio-demographic factors. Significantly, antenatal care utilization of mothers strongly influenced MCV1 coverage and age recommended MCV1 coverage in India. The study also identified that children who missed MCV1 had one or more adverse health risks such as malnutrition, anemia and diarrhea disease.

Conclusions: A socio-economic gradient exists in India's MCV1 coverage, mediated by antenatal visits, education of mothers, and highlighted socio-demographic factors. Infection with measles was significantly correlated with greater anthropometric deficits among the study cohort, indicating a wider range of benefits from preventing measles infection. Eliminating morbidity and mortality from measles in India is feasible, although it will require efficient expanded program on immunization management, enhanced health literacy among mothers, continuing commitment from central state and district political authorities.

Keywords: India, Measles, National Family Health Survey 4, MCV1

\footnotetext{
* Correspondence: suyash.mishra@iips.net

${ }^{1}$ International Institute for Population Sciences (IIPS), Mumbai, India

Full list of author information is available at the end of the article
}

(c) The Author(s). 2020 Open Access This article is licensed under a Creative Commons Attribution 4.0 International License, which permits use, sharing, adaptation, distribution and reproduction in any medium or format, as long as you give appropriate credit to the original author(s) and the source, provide a link to the Creative Commons licence, and indicate if changes were made. The images or other third party material in this article are included in the article's Creative Commons licence, unless indicated otherwise in a credit line to the material. If material is not included in the article's Creative Commons licence and your intended use is not permitted by statutory regulation or exceeds the permitted use, you will need to obtain permission directly from the copyright holder. To view a copy of this licence, visit http://creativecommons.org/licenses/by/4.0/ The Creative Commons Public Domain Dedication waiver (http://creativecommons.org/publicdomain/zero/1.0/) applies to the data made available in this article, unless otherwise stated in a credit line to the data. 


\section{Background}

Measles is considered as one of the leading vaccinepreventable causes of child mortality and morbidity worldwide [1-3]. The World Health Organization (WHO) reported that 142,000 measles-related deaths occurred globally in 2018, compared with annual deaths of 2.6 million children prior to the introduction of the measles vaccine in 1963. During 2000-2017, the number of measles cases reported worldwide decreased by $80 \%$, from 853,479 in 2000 to 173,330 in 2017 , and measles incidence decreased by $83 \%$, from 145 to 25 cases per million population [4]. Global measles incidence, morbidity and mortality trends improved over the past six decades until a reversal in the downward incidence trend was observed between early 2018 and late 2019, with global measles cases tripling in the first half of 2019 compared with the corresponding period of 2018 [3, 5, 6]. Current trends indicate that around 21 million children missed the first dose of measles vaccination every year between 2010 and 2017 globally, which directly influences measles outbreaks, morbidity, and mortality. In 2019, highest numbers of measles cases were reported from Madagascar, Ukraine, India, Nigeria, Kazakhstan, Chad, Myanmar, Thailand, and the Philippines [6-8]. Spikes in cases of measles not only affect low-income countries, but also developed countries in terms of human as well as economic losses [5, 9-15].

Measles-related deaths and complications are also linked to sustainable national and global development, in part because measles infection attenuates pre-existing protective antibodies for other infections [16]. It is postulated that measles immune suppression mainly results from the depletion of immune cell subsets, which is masked by the rapid proliferation of measles virusspecific lymphocytes, hence the measles paradox of life long immunity to measles following infection despite increased susceptibility to other microbial infections [17]. Immunization plays a key role in facilitating the achievement of 14 out of the 17 Sustainable Development Goals (SDGs), and mirrors SDG's key ethos - "leaving no one behind". For example, with goal two of SDGs of zero hunger, undernourished children who contract measles are more likely to die from infectious diseases such as diarrhea, and pneumonia. Many of the non-measles infections are also vaccine-preventable.

About 2.9 million children missed the first dose of measles vaccine between 2010 and 2017 in India, which is one of the reasons behind the high level of measles-related morbidity and mortality in the country [18]. Measles vaccination coverage (MCV1) in India improved significantly from $51 \%$ in 1999 to $81 \%$ in 2016 , less than the $86 \%$ coverage documented globally for 2016 [19]. Between 2009 and 2011, however, 39\% of confirmed measles cases in Pune, India were previously vaccinated with MCV1, suggestive of deficiencies in vaccine cold chain and program effectiveness [20]. Age inappropriate vaccination, failure of maintaining cold chain, and chronic malnutrition are probable reasons for measles cases among those previously vaccinated against measles [21]. Globally, vaccination with a second dose of measles-containing vaccine (MCV2) reached 64\% in 2016, quadrupling the 2000 estimate. Studies have indicated that measles infection is rare in individuals who have received both doses of measlescontaining vaccine [22]. The government of India introduced the MCV2 in 2010 among all the states and union territories in various phases. Surveillance-based studies in different areas in India have demonstrated positive correlations with optimal MCV2 vaccination and reduced rates of measles-related mortality [23-26].

It is noteworthy that in February 2017, India's health ministry launched a phased nationwide single shot measles-rubella vaccination campaign which aims to vaccinate 410 million children in the age group 9 months to 15 years, across the country [27]. This revitalization of measles vaccination may account for the unique measles trend in India between 2018 and 2019, with a 74\% reduction in measles cases, in contrast to a $300 \%$ increase in measles cases reported globally during the same period. In 2015 , there were 83,026 cases of measles documented by India's health ministry. Following the successful implementation of the 2017 measles and rubella campaigns the confirmed measles cases in India dropped to 10,695. Earlier measles vaccination campaigns in India, such as the 2010 two dose measles campaign are estimated to have saved the lives of 41,000-56, 000 children between 2010 and 2013 - equivalent to $39-57 \%$ of the expected number of measles deaths nationwide [26]. Despite the remarkable progress in measles control, India still has the fourth highest measles caseload globally [12].

This study expands on the existing knowledge pool on socio-demographic correlates of measles vaccination in four important areas. First, studies in India based using various dataset studied patterns of MCV1 coverage at key administrative levels [28-31]. However, the recent NFHS provides an opportunity to further understand more recent patterns MCV1 coverage at district level, explored in some study [32,33]. Second, the study seeks to ascertain the age recommended schedule of MCV1. To the best of our knowledge, only one study which focused on the age-recommended vaccination schedule for MCV1 was conducted using NFHS-3 (2005-06) data [34]. Third, studies in India have established the impact of various socio-economic correlates of uptake of MCV1 in India. However, we are not aware of any study that has established the linkage of antenatal care visits on MCV1 coverage, based on NFHS-4 data. Lastly, no studies in India based on NFHS-4 data has established the 
potential impact of measles vaccination on malnutrition, anemia, and diarrhea. In this context, the present study tries to examine the coverage of MCV1, its variation across the various population subgroup, and its associated covariates using data from the most recent round National Family Health Survey (NFHS-4).

\section{Methods}

\section{Data source}

The authors analyzed the unit data from the fourth round of the National Family Health Survey (NFHS-4) conducted during 2015-16. NFHS is the Indian version of the Demographic Health Survey (DHS), providing detailed information on the nutritional status of children and family members, as well as information on utilization of health care services, and socio-economic and demographic characteristic of the households, etc. NFHS-4 collected information from 601,509 households, comprising of 699,686 ever-married females in 15-49 age group and 112,122 males in 15-54 age group. The instrument used, results of the survey, along with the methodology, and sampling design are available in the NFHS-4 national report [19].

The unit of analysis of this study are children aged $12-23$ months. A total of 259,627 children were included in the survey, out of which 48,752 belonged to the age group 12-23 months. The selection of this age group to calculate the estimations are as per the DHS guidelines [35]. Out of the total sample of 48, 752 children, 9222 did not receive MCV1. For estimating the recommended vaccination schedule, we have included only those children who had received
MCV1 and for whom the months of the vaccinations were available. As, the month of vaccination was not reported for 15,304 children, the total sample size for the estimation of vaccination at recommended age included the 24,226 children. Detailed information about the selection of the sample is provided in the schematic diagram (Fig. 1).

\section{Outcome variables}

We used two outcome variables in the study. The first is the MCV1 vaccination status, and second is MCV1 status at the recommended age which is between nine and twelfth months, as per India's 2019 immunization guidelines (https://www.nhp.gov.in/measles-immunizationday_pg). The "kid's file" of the NFHS provides detailed information on all vaccination to all surviving children. The information is based on the reported data on children's vaccination card. In case of unavailability of vaccination card, the mother's oral information was taken into account. We used the compiled NFHS-4 information to estimate the coverage and associated covariates of MCV1 in India.

\section{Independent variables}

A set of independent variables guided by literature were used in the analysis. These variables included the child's characteristics such as sex and birth order of the child. Maternal characteristics such as mother's age (15-24, $25-34,35$ and above), education (illiterate, primary, secondary, higher), antenatal care (ANC) coverage and media exposure were included in the analysis. The ANC coverage was defined as sufficient if the mother had

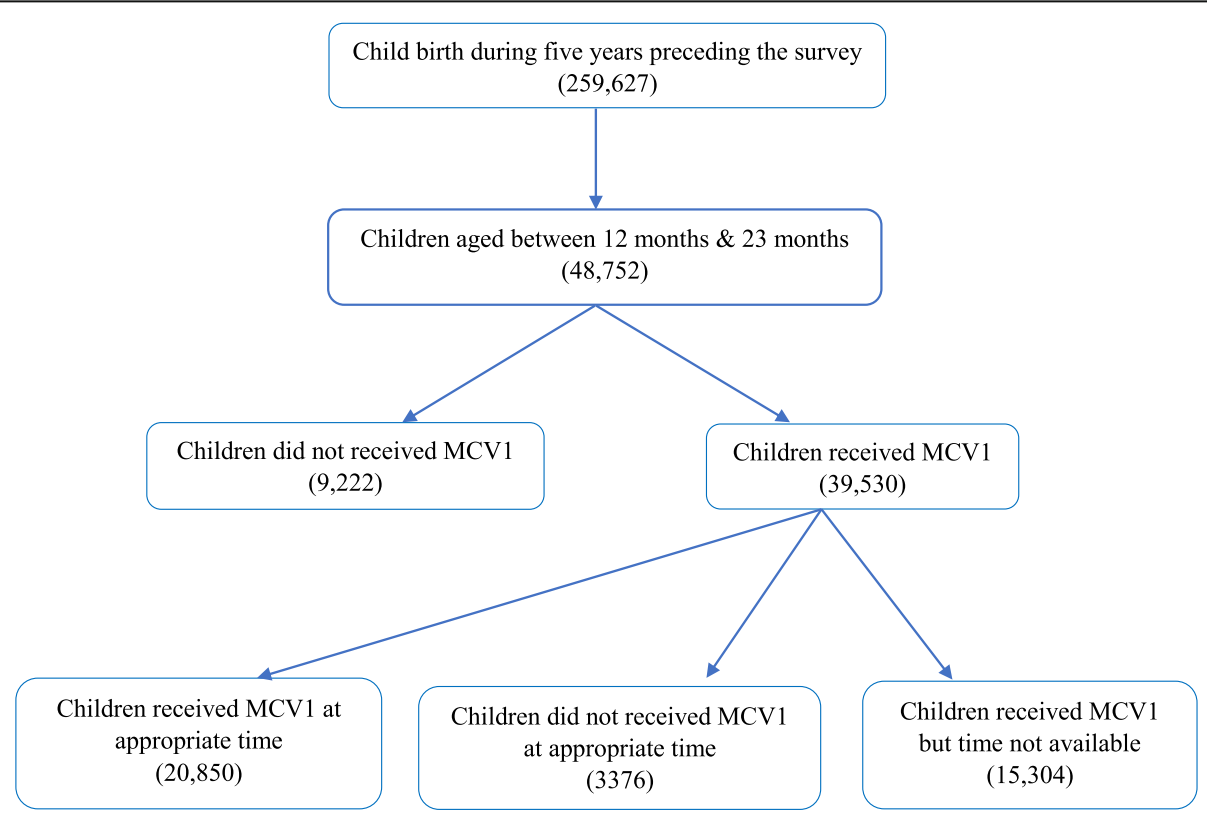

Fig. 1 Schematic presentation of first dose of measles vaccination (MCV1) in India, 2015-16 
completed at least four antenatal visits during the pregnancy period for the index child. The media exposure of mother was defined as having access to either newspaper, television or radio. In addition, some household characteristics such as place of residence (rural /urban), wealth quintile (poorest, poorer, middle, richer, richest), religion (Hindu, Muslim, others), and social group (schedule tribe, schedule caste, other backward class and other) were included in the study. The wealth status of the household was computed from the wealth factor score using principal component analysis techniques from the set of assets and facilities used in the household.

\section{Statistical analysis}

Bivariate and multivariate analyses were used in the study. Bivariate analysis was used to understand the coverage of MCV1 and MCV1 vaccination at recommended age across various states, districts and population subgroups in India. To understand the spatial variation across the districts of India, the spatial map was created using GeoDA 1.14 software. Binary logistic regression (state fixed effect model) was used to identify significant predictors of MCV1 vaccination as well as MCV1 vaccination at recommended age. The outcome variable was coded as 1 for those children who received MCV1 and 0 otherwise. Similarly, for the second outcome variable and MCV1 at recommended age was considered as 1 if the children had received MCV1 based on recommended age and 0 otherwise. The general formula for regression model is given as:

$$
\begin{aligned}
& \operatorname{logit}\left(\pi_{i}\right)=\alpha+\beta_{1}\left(\text { place of residence }{ }_{i}\right) \\
& \left.+\beta_{2} \text { (mother's age }{ }_{i}\right) \\
& \left.+\beta_{3} \text { (education level }{ }_{i}\right) \\
& \left.+\beta_{4} \text { (birth order }{ }_{i}\right)
\end{aligned}
$$

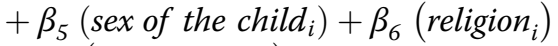

$$
\begin{aligned}
& +\beta_{7}\left(\text { social group }_{i}\right) \\
& \left.+\beta_{8} \text { (wealth quintile }{ }_{i}\right) \\
& \left.+\beta_{9} \text { (media exposure }{ }_{i}\right) \\
& +\beta_{10} \text { (mothers with sufficient } A N C_{i} \text { ) } \\
& +\beta_{11} \text { (place of delivery }_{i} \text { ) } \\
& \left.+\beta_{12} \text { ( } \text { place of vaccination }_{i}\right)+e_{i} \text {, }
\end{aligned}
$$

where $\pi_{i}$ is the probability of the $\mathrm{i}^{\text {th }}$ child receiving measles vaccination, $\alpha$ is the intercept, $\beta_{1}$ 's are the slope parameters and $\mathrm{e}$ is the error term.

The analysis was carried out using STATA version 15 [36].

\section{Results}

Sample characteristics of the children

Table 1 presents the socio-economic and demographic characteristics of the sample population. About $71.6 \%$ (95\% CI: 70.9-72.3) of the children resided in rural areas. With regards to educational attainment, 27.7\% (95\% CI: 27.2-28.3) of mothers had no education, while $22.3 \%$ (95\% CI: $21.7-22.9$ ) of mothers in the study had attained higher education. About a quarter of children belonged to the household from poorest quintile (24.6\%), whereas $15 \%$ belonged to the richest quintile. With respect to the place of delivery and place of MCV1 vaccination, $82.2 \%$ (95\% CI: 81.7-82.6) of children delivered in health facility (either public or private) while 90.7\% (95\% CI: 90.2-91.2) were vaccinated in a public health center.

\section{Coverage of MCV1 across various geographic levels and population subgroups}

MCV1 coverage data showed major variations across the geographic boundaries of India (Fig. 2). The national average of MCV1 coverage was $81.2 \%$ and varied largely across the states of India. Fourteen states reported lower MCV1 coverage compared to the national average whereas six states reported more than $90 \%$ uptake of MCV1. These states with lower MCV1 coverage than national average were economically and demographically disadvantaged states of India with the exception of Haryana and Gujarat. The coverage of MCV1 varied from $50.3 \%$ in Nagaland, followed by $54.7 \%$ in Arunachal Pradesh and 61.7\% in Mizoram to $93.9 \%$ in Chhattisgarh followed by $93.3 \%$ in Sikkim and 93.2\% in Punjab.

Figure 3 represents the spatial mapping of the MCV1 coverge across the 640 districts of India. A total of 22 districts had the coverage below 50\%, 148 districts had MCV1 coverage of between $50 \%$ and $75 \%$, whilist 470 districts had the coverage of more than $75 \%$. The coverage of MCV1 was lowest in the districts of East Kameng (17.5\%), followed by Bahraich (27\%) and Kurung Kumey (30.8\%). The lagging districts in terms of MCV1 coverage were mainly from the states of Arunachal Pradesh, Nagaland, Manipur, Uttar Pradesh, Rajasthan and Madhya Pradesh.

Figure 4 presents the coverage of coverage of MCV1 at recommended age across the states of India. The national average of MCV1 coverage at recommended age was $85.4 \%$ and varied substantially across the states of India. Eleven states reported lower MCV1 coverage at recommended age compared to national average whereas seven states had coverage of more than $90 \%$. The coverage was lowest in Bihar (76.4\%) followed by Uttar Pradesh (79.9\%) and Tamil Nadu (80.1\%) whereas it was highest in West Bengal (96.2\%) followed by Mizoram (92.9\%) and Odisha (92.5\%).

Figure 5 provides the timing of MCV1 in India. Although the uptake of vaccination has improved over the past two decades in India, the recommended MCV1 
Table 1 Sample distribution of the study population

\begin{tabular}{|c|c|c|}
\hline Variables & Percentage (\%) & 95\% Confidence Interval \\
\hline \multicolumn{3}{|l|}{ Place of Residence } \\
\hline Urban & 28.4 & $(27.7,29.1)$ \\
\hline Rural & 71.6 & $(70.9,72.3)$ \\
\hline \multicolumn{3}{|l|}{ Mother's age } \\
\hline $15-24$ & 43.2 & $(42.5,43.8)$ \\
\hline $25-34$ & 55.6 & $(54.9,56.2)$ \\
\hline $35+$ & 1.3 & $(1.1,1.4)$ \\
\hline \multicolumn{3}{|l|}{ Education Level } \\
\hline No education & 27.7 & $(27.2,28.3)$ \\
\hline Primary & 13.8 & $(13.3,14.2)$ \\
\hline Secondary & 36.2 & $(35.6,36.8)$ \\
\hline Higher & 22.3 & $(21.7,22.9)$ \\
\hline \multicolumn{3}{|l|}{ Birth order } \\
\hline 1 & 38.0 & $(37.4,38.7)$ \\
\hline 2 & 33.2 & $(32.6,33.8)$ \\
\hline 3 & 15.3 & $(14.9,15.8)$ \\
\hline $4+$ & 13.5 & $(13.1,13.8)$ \\
\hline \multicolumn{3}{|l|}{ Sex of the child } \\
\hline Male & 51.9 & $(51.2,52.5)$ \\
\hline Female & 48.1 & $(47.5,48.8)$ \\
\hline \multicolumn{3}{|l|}{ Religion } \\
\hline Hindu & 78.3 & $(77.7,78.9)$ \\
\hline Muslim & 16.9 & $(16.4,17.4)$ \\
\hline Others & 4.8 & $(4.5,5.1)$ \\
\hline \multicolumn{3}{|l|}{ Social Group } \\
\hline Schedule Caste & 21.4 & $(20.8,21.9)$ \\
\hline Schedule Tribe & 10.3 & $(10.0,10.7)$ \\
\hline $\mathrm{OBC}$ & 44.1 & $(43.5,44.8)$ \\
\hline Others & 24.2 & $(23.6,24.8)$ \\
\hline \multicolumn{3}{|l|}{ Wealth Quintile } \\
\hline Poorest & 24.6 & $(24.1,25.1)$ \\
\hline Poorer & 21.5 & $(21.0,22.0)$ \\
\hline Middle & 20.2 & $(19.7,20.8)$ \\
\hline Richer & 18.7 & $(18.1,19.3)$ \\
\hline Richest & 15.0 & $(14.4,15.5)$ \\
\hline \multicolumn{3}{|l|}{ Media Exposure } \\
\hline No & 26.2 & $(25.6,26.7)$ \\
\hline Yes & 73.8 & $(73.3,74.5)$ \\
\hline \multicolumn{3}{|c|}{ Mother with sufficient ANC } \\
\hline$<4$ & 49.2 & $(48.5,49.9)$ \\
\hline $4+$ & 50.8 & $(50.1,51.5)$ \\
\hline \multicolumn{3}{|l|}{ Place of Delivery } \\
\hline Institutional Delivery & 82.2 & $(81.7,82.6)$ \\
\hline Delivered at home & 17.8 & $(17.4,18.3)$ \\
\hline \multicolumn{3}{|l|}{ Place of vaccination } \\
\hline Public health center & 90.7 & $(90.2,91.2)$ \\
\hline Private health center & 9.3 & $(8.8,9.8)$ \\
\hline
\end{tabular}




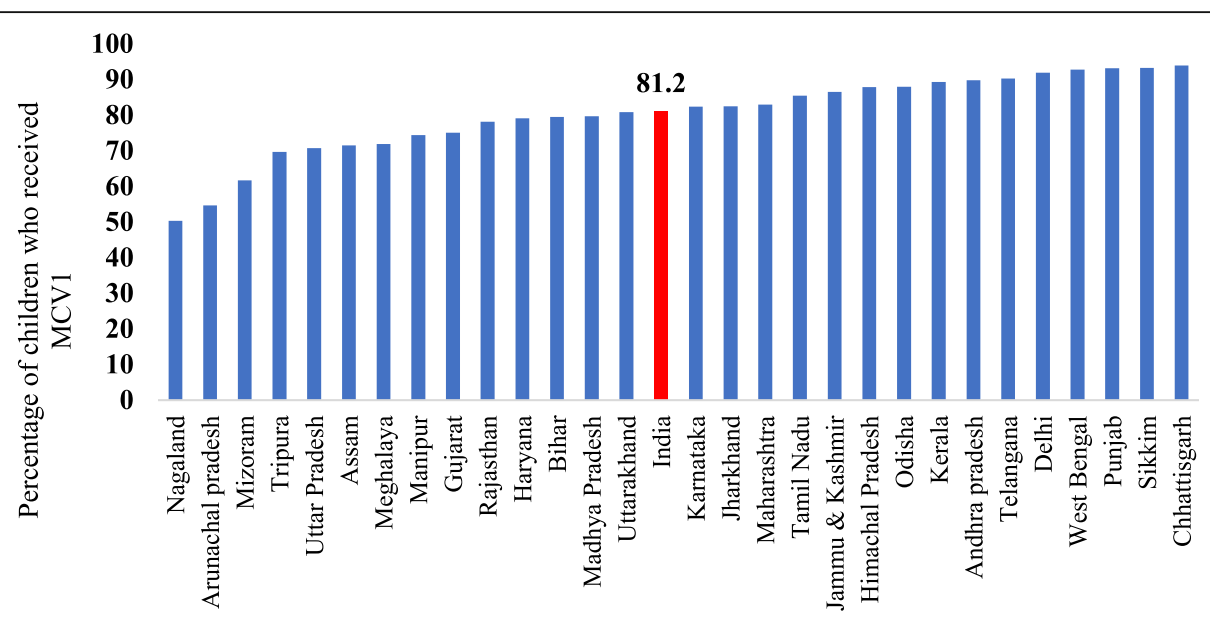

Fig. 2 State variation in measles vaccination (MCV1) coverage in India 2015-16

scheduled remains suboptimal. About $85.5 \%$ children were vaccinated against MCV1 between 9 and 12 months which is the recommended timing for MCV1 vaccination, $7.2 \%$ of children were vaccinated prior to recommended age, while another $7.2 \%$ children were vaccinated after 12 months. Early MCV1 (i.e. 8 months or less) may lead to vaccine failure due to partial neutralization by maternal antibodies, whereas late vaccination (after 12 months in India) may increase the vulnerability of such children to measles infection.

\section{Socio economic characteristics and health impact of measles vaccination among children}

The study analyzed the socio-economic as well as health status of the children who had ever received the measles vaccination, those who had not taken it,

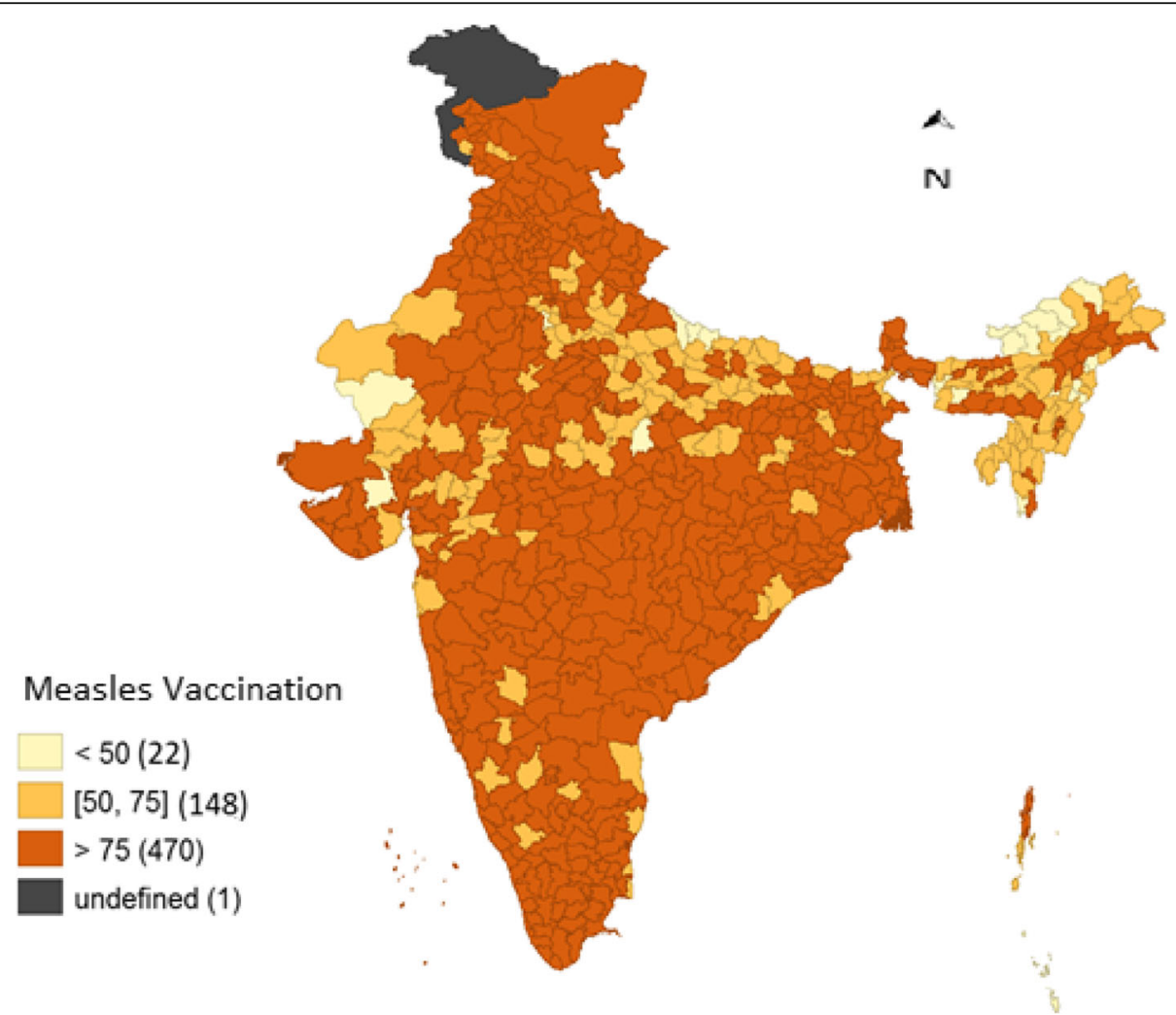

Fig. 3 Level of measles vaccination (MCV1) coverage in the districts of India, 2015-16. Source: Author's prepared map using NFHS-4 data (2015-16) 


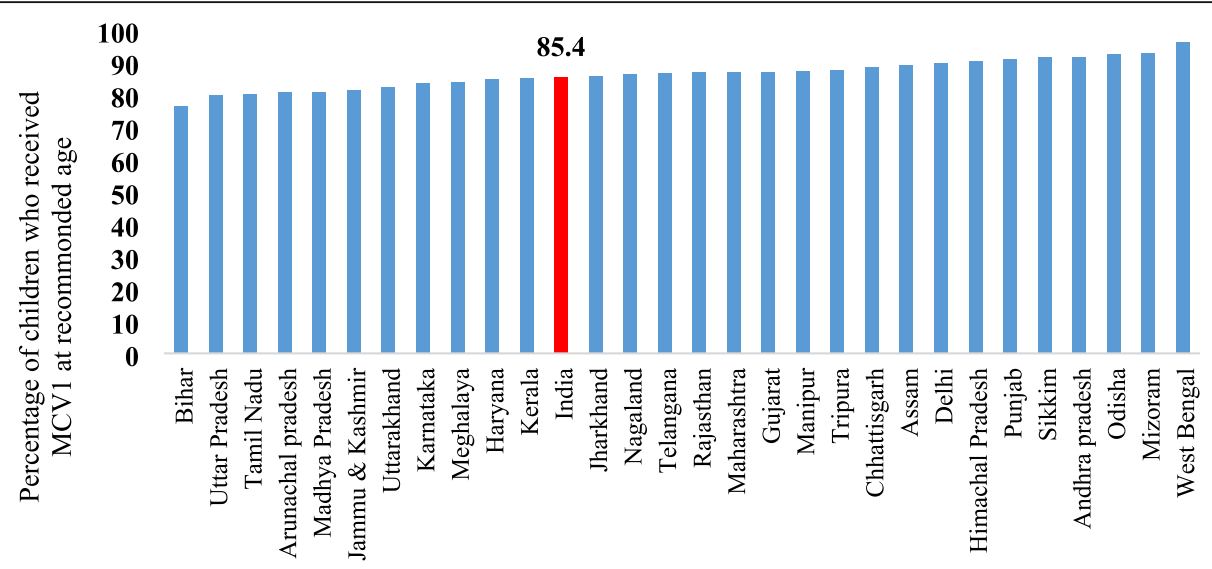

Fig. 4 State variation in MCV1 coverage at recommended age in India, 2015-16

and children who had taken it at recommended age (Table 2). The table provides evidence that the children who had not received the measles vaccination were more disadvantaged compared to the other two sub-groups in term of socio economic status as well the health status. A higher proportion of children who had not received measles vaccination were from poor wealth group and resided in rural areas. The mothers of children who were not vaccinated against MCV1 had comparatively low levels of education and had undertaken less antenatal visits as compared to mothers whose children were vaccinated.

The children who received MCV1 at recommended age had better health status than those who did not received the vaccine. For example, $39.2 \%$ of children were stunted among the children who had received MCV1 at recommended age, while $48.4 \%$ were stunted among those who had not been administered MCV1. Similarly, the prevalence of diarrhea was higher among the children who had not received MCV1. This infers that not only, vaccinating children against measles is important, but vaccinating at recommended age is also essential for children's optimal health.

\section{Correlates of measles vaccination in India}

Socio-economic status, educational level, media exposure, and 4+ ANC visits among mothers played a vital role in influencing MCV1 uptake in India (Appendix 1). Mothers who received higher education were more likely to vaccinate their children against MCV1 compared to mothers who only had primary education or no education. The chi-square statistic showed a significant relationship between uptake of MCV1 (chi-sqaure $=1400$; $p$-value $=0.000)$, recommended vaccination schedule of MCV1 (chi-sqaure $=95.81 ; p$-value $=0.000$ ) and education level of the mothers. The uptake of MCV1 was higher among children from mothers with higher education $(87.9 \%$; $95 \%$ CI: $86.9-88.9)$ compared to mothers with no education (71.4\%; 95\% CI: 70.4-72.4). Similar pattern was observed in case of children who received MCV1 at recommended age. Apart from these variables, other variables such as place of residence, mother's age, educational status, mass media exposure, child birth order, wealth quintile, place of delivery, place of vaccination and mother's visit of antenatal care were found to be significant predictors of MCV1 in India (Table 3). For instance, the children whose mothers had undertaken 4

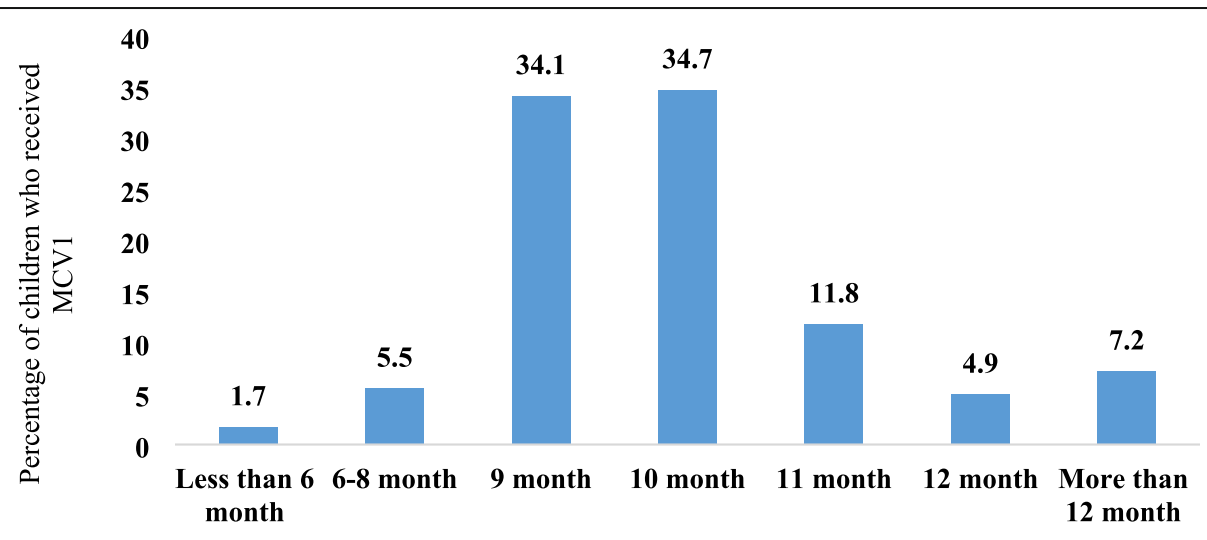

Time to MCV1

Fig. 5 Timing of measles vaccination (MCV1) in India, 2015-16 
Table 2 Characteristics of children who were vaccinated, who were not vaccinated and who were vaccinated at recommended age against first dose of measles in India 2015-16

\begin{tabular}{|c|c|c|c|}
\hline Characteristics & $\begin{array}{l}\text { Children who had received } \\
\text { measles vaccination }\end{array}$ & $\begin{array}{l}\text { Children who had not received } \\
\text { measles vaccination }\end{array}$ & $\begin{array}{l}\text { Children who had received measles } \\
\text { at recommended age (9-12 months) }\end{array}$ \\
\hline $\begin{array}{l}\text { Mean education level of } \\
\text { mother (in years) }\end{array}$ & $7.1[7.0-7.2]$ & $5.0[4.9-5.1]$ & $7.7[7.6-7.8]$ \\
\hline $\begin{array}{l}\text { Percentage of mother have } \\
4+\text { ANC }\end{array}$ & $54.7[53.9-55.4]$ & $34.0[32.5-35.5]$ & $60.8[59.7-61.8]$ \\
\hline Percentage Stunted & $41.4[40.7-42.1]$ & $48.4[46.9-49.9]$ & $39.2[38.2-40.2]$ \\
\hline Percentage Underweight & $34.1[33.3-34.7]$ & $39.7[38.3-41.2]$ & 31.9 [30.9-32.9] \\
\hline Suffered from anemia & $42.2[41.5-42.9]$ & $46.9[45.4-48.3]$ & 39.9 [38.8-40.9] \\
\hline Suffered from diarrhea/fever & $24.2[23.6-24.8]$ & $26.5[25.3-27.7]$ & $24.6[23.7-25.5]$ \\
\hline $\begin{array}{l}\text { Percentage from lowest } 40 \% \\
\text { of wealth quintile. }\end{array}$ & $43.1[42.5-43.9]$ & $59.0[57.5-60.4]$ & $38.8[37.8-40.0]$ \\
\hline $\begin{array}{l}\text { Percentage from SC/ } \\
\text { ST category. }\end{array}$ & $31.4[30.7-32.1]$ & $33.2[31.9-34.5]$ & 30.6 [29.7-31.6] \\
\hline No. of Sample & 39,530 & 9222 & 20,850 \\
\hline
\end{tabular}

or more antenatal visits were 52\% (AOR: 1.52; $95 \% \mathrm{CI}$ : 1.43-1.63) more likely to be vaccinated against MCV1, compared with children whose mothers undertook less than four antenatal visits. Furthermore, compared with children of first birth order, the probability of receiving MCV1 was 27\% (AOR: 0.73; 95\% CI: 0.67-0.81) lower for children of birth order 4 and above. Children who were delivered at home had 27\% (AOR: 0.73; 95\% CI: 0.68-0.78) lower likelihood of receiving MCV1 compared with children born in healthcare facilities.

\section{Discussion}

The present study addressed the four major key previously under-explored research areas, which complements the existing knowledge on MCV1 vaccination and its impact on child health. First, our findings reveal considerable inter-district variations in MCV1 vaccination uptake in the districts of India. Second, among children who had received MCV1 vaccination, around 15\% did not receive it at recommended age. This pattern varied across the states and districts of India. Third, the study exhibited the significant positive impact of at least four antenatal care visits of mothers on MCV1 vaccination among the children in India. Moreover, we found that failure to receive MCV1 has an adverse impact on malnutrition, anemia and diarrheal diseases among children. These contributions are further discussed below.

We found that 22 districts of India had lower than 50\% of MCV1 coverage. The spatial clusters of districts with lower uptake of MCV1 was found in Nagaland, Manipur, Arunachal Pradesh, Rajasthan, Madhya Pradesh, and Uttar Pradesh. Districts with lower coverage of MCV1 need to be focussed on for universalisation of the MCV1 coverage. Moreover, a significant difference was found among the districts within the states. Of the 22 districts, majority belonged to north-eastern part of India. The possible reason for the poor immunization coverage can be attributable to inadequate health infrastructure, accessibility and acceptability of services and poverty [32, 33]. India's Expanded Program on Immunization should prioritize efforts to address reasons for dropout e.g. forgetfulness and long distance among these disadvantaged districts.

The MCV1 coverage at recommended age was found to be high using the post-2017 criterion of age range 912 months for the vaccination and varies across the states and districts of India. However, $15 \%$ of children at national level who had received MCV1, did not get it in the recommended age based on national vaccine scheduled. Major factors precluding vaccination at recommended age were low maternal education and suboptimal maternal health care utilisation. The odds in timely vaccination are found higher in rural areas as compared to urban counterparts. Rural infrastructure has developed enormously in India after implementation of National Rural Health Mission since 2005. The rural areas are in the continuous focus of the national as well as the state government. However, the urban disadvantage may be due to the slum population. However, we did not found any gender differential in agerecommended vaccination.

The study established significant association between antenatal care and institutional delivery with the MCV1 coverage as well as the MCV1 at recommended age in India. Antenatal care is one of the strategies which is not only linked with maternal and child health during pregnancy period but also affects postnatal and childhood health $[37,38]$. The higher positive 
Table 3 Adjusted odds ratio and 95\% confidence interval of socio economic correlates of measles vaccination (MCV1) and MCV1 at appropriate time in India

\begin{tabular}{|c|c|c|c|c|}
\hline \multirow[t]{2}{*}{ Variables } & \multicolumn{2}{|c|}{ MCV1 Vaccination } & \multicolumn{2}{|c|}{ MCV1 at Recommended Age } \\
\hline & $\overline{\mathrm{AOR}}$ & $95 \% \mathrm{Cl}$ & $\overline{\mathrm{AOR}}$ & $95 \% \mathrm{Cl}$ \\
\hline \multicolumn{5}{|c|}{ Place of Residence } \\
\hline \multicolumn{5}{|l|}{ Urban $^{\oplus}$} \\
\hline Rural & $1.25^{* * *}$ & $(1.16,1.35)$ & $1.13^{* *}$ & $(1.02,1.23)$ \\
\hline \multicolumn{5}{|l|}{ Mother's age } \\
\hline \multicolumn{5}{|l|}{$15-24^{\oplus}$} \\
\hline $25-34$ & $1.33^{* * *}$ & $(1.25,1.42)$ & 1.05 & $(0.96,1.14)$ \\
\hline $35+$ & $1.34^{* * *}$ & $(1.10,1.65)$ & 0.80 & $(0.58,1.06)$ \\
\hline \multicolumn{5}{|c|}{ Education Level } \\
\hline \multicolumn{5}{|c|}{ No education ${ }^{\circledast}$} \\
\hline Primary & $1.18^{* * *}$ & $(1.08,1.28)$ & $1.10^{* *}$ & $(1.02,1.32)$ \\
\hline Secondary & $1.36^{* * *}$ & $(1.26,1.47)$ & $1.21^{* * *}$ & $(1.14,1.41)$ \\
\hline Higher & $1.59^{* * *}$ & $(1.43,1.77)$ & $1.34^{* * *}$ & $(1.13,1.48)$ \\
\hline
\end{tabular}

Birth order

$1^{\circledR}$

2

3

$0.90^{* *}$

$(0.84,0.97)$

0.99

$(0.90,1.08)$

$4+$

$0.77^{* * *}$

$(0.70,0.84)$

$(0.84,1.08)$

$0.73^{* * *}$

$(0.67,0.81)$

$(0.93,1.24)$

Sex of the child

$$
\begin{aligned}
& \text { Male } \\
& \text { Female }
\end{aligned}
$$

\section{Religion}

Hindu ${ }^{\oplus}$

Muslim

Others

\section{Social Group}

Schedule Caste ${ }^{\circledast}$

Schedule Tribe

$\mathrm{OBC}$

Others

\section{Wealth Quintile}

Poorest ${ }^{\oplus}$
Poorer
Middle
Richer
Richest

Media Exposure

$\mathrm{No}^{\oplus}$

Yes

Mother ANC visit

$<4^{\circledR}$

$4+$

Place of Delivery
0.96

$(0.91,1.01)$

0.99

$(0.92,1.07)$

$0.62^{* * *}$

0.89

$(0.57,0.68)$

$(0.77,1.02)$

0.93

$(0.82,1.05)$

$(0.87,1.25)$

1.03

$1.04^{* *}$

$(0.90,1.22)$

$(0.97,1.13)$

1.11

$(1.01,1.24)$

$(0.95,1.15)$

1.01

$(0.89,1.14)$
$(1.07,1.25)$

$(1.25,1.51)$

$(1.39,1.74)$

$(1.67,2.22)$

$1.93^{* * *}$

$1.12^{* * *}$

$1.52^{* * *}$

$(1.43,1.63)$

$1.21^{* * *}$

$(1.11,1.32)$
$(0.97,1.24)$

$(1.06,1.41)$

$(1.12,1.53)$

$(0.93,1.33)$
$(0.92,1.15)$

$(1.04,1.20)$

1.03

$1.22^{* *}$

1.11

$(1.11,1.32)$ 
Table 3 Adjusted odds ratio and 95\% confidence interval of socio economic correlates of measles vaccination (MCV1) and MCV1 at appropriate time in India (Continued)

\begin{tabular}{|c|c|c|c|c|}
\hline \multirow[t]{2}{*}{ Variables } & \multicolumn{2}{|c|}{ MCV1 Vaccination } & \multicolumn{2}{|c|}{ MCV1 at Recommended Age } \\
\hline & AOR & $95 \% \mathrm{Cl}$ & $\mathrm{AOR}$ & $95 \% \mathrm{Cl}$ \\
\hline \multicolumn{5}{|c|}{ Institutional Delivery ${ }^{\circledast}$} \\
\hline Delivered at home & $0.73^{* * *}$ & $(0.68,0.78)$ & $0.80^{* * *}$ & $(0.72,0.89)$ \\
\hline \multicolumn{5}{|l|}{ Place of vaccination } \\
\hline \multicolumn{5}{|l|}{ Public ${ }^{\oplus}$} \\
\hline Private & $0.59^{* * *}$ & $(0.54,0.66)$ & $0.82^{* * *}$ & $(0.71,0.96)$ \\
\hline
\end{tabular}

*** $p<.01,{ }^{* *} p<.05,{ }^{*} p<0.10$; Reference category

effect of optimal ANC attendance on the MCV1 could be due to greater amount of information about immunisation services, and education on the benefits of routine immunisation during ANC visits. Mothers who had institutional birth are more likely to be aware about the importance of the MCV1 vaccination. In line with previous studies, we also found that maternal education and the household economic status were positively correlated with MCV1 vaccination in India $[9,18]$.

Uptake of MCV1 and receiving it at recommended age is critical, as it reduces the risk from disease. Measles vaccination at earlier than 9 month is subject to increased risk of vaccine attenuation by maternal antibodies, while vaccination after the age of 12 months leave children susceptible to measles at a period during which protective maternal antibodies have waned. Further, the study established that children who were vaccinated at recommended age had better health status than the children who had not received it. Children who had not received MCV1 were found to be more prone to stunting, wasting and underweight than vaccinated children. This infers that the MCV1 vaccination has a negative correlation with the malnutrition status of the children. We also found that, the children who had not received MCV1 were more likely to suffer from fever, diarrhea, anaemia and malnutrition [39]. A distinct social gradient permeates India's measles vaccination coverage, with children of parents with higher education and wealth more likely to be vaccinated with MCV1 compared with children born to socioeconomically vulnerable mothers. Our analysis revealed that the consequences of measles infection extend to severe malnutrition and greater susceptibility of unvaccinated children to anaemia and diarrhoeal infections. Thus, there are multiple health benefits of the uptake if MCV1 beyond protection from measles infection.

\section{Limitations}

There are two important limitations of this study. First, the estimates of coverage are only based on the first dose of the measles (MCV1) vaccination, as no data was available regarding the second dose of measles (MCV2) vaccination in the NFHS-4 survey. Secondly, nationally representative information on deaths and complications due to measles were not available in the NFHS-4 dataset. Therefore, we were unable to map trends in vaccination coverage with measlesrelated morbidity and mortality.

\section{Conclusion}

Various identifiable and amenable geographical, predisposing and enabling factors are associated with the coverage of MCV1 and age recommended MCV1 vaccination in India. Among other identified factors, maternal health care utilization such as recommended antenatal care among mother have highly impacted the MCV1 coverage in India. This study highlights pathways for assuring equity in measles vaccination, through consideration of social determinants of vaccination coverage such as low utilization of antenatal facilities by mothers. $[40,41]$. The authors also provide insights into approaches for improving vaccination quality through achieving age-recommended vaccination. Further, the study recommends universalisation of MCV1 and addressing all the possible reasons for dropout. India since mid-2017 have made impressive strides in improving measles vaccination with the effective implementation of a national measles-rubella vaccination program. This demonstrates the importance of effective leadership and management, through which evidence-based approaches may be applied to sustain the improvements by addressing social and structural encumbrances to measles vaccination.

Abbreviations

UNICEF: United Nations International Children's Emergency Fund; MCV1: Measles-containing-vaccine first-dose; MCV2: Measles-containingvaccine second-dose; NFHS: National Family Health Survey 


\section{Appendix}

Appendix 1 Distribution of children who received MCV1 and those who received MCV1 at appropriate time by selected background characteristics in India, 2015-16

\begin{tabular}{|c|c|c|c|c|}
\hline \multirow[t]{2}{*}{ Variables } & \multicolumn{2}{|c|}{ MCV1 Vaccination } & \multicolumn{2}{|c|}{ MCV1 at Recommended Age } \\
\hline & $\begin{array}{l}\text { Percentage } \\
(95 \% \text { Cl) }\end{array}$ & $\begin{array}{l}\text { Chi-square statistic } \\
\text { (P-value) }\end{array}$ & $\begin{array}{l}\text { Percentage } \\
(95 \% \mathrm{Cl})\end{array}$ & $\begin{array}{l}\text { Chi-square statistic } \\
(\boldsymbol{P} \text {-value) }\end{array}$ \\
\hline \multicolumn{5}{|l|}{ Sex of the child } \\
\hline Male & $81.7(81.0,82.4)$ & $4.38(0.036)$ & $85.8(85.0,86.6)$ & $0.13(0.721)$ \\
\hline Female & $80.4(79.7,81.1)$ & & $86.3(85.4,87.1)$ & \\
\hline \multicolumn{5}{|l|}{ Birth order } \\
\hline 1 & $84.7(83.9,85.4)$ & $845.60(0.000)$ & $87.4(86.5,88.3)$ & $25.88(0.000)$ \\
\hline 2 & $83.1(82.2,83.9)$ & & $86.3(85.2,87.3)$ & \\
\hline 3 & $77.6(76.3,78.9)$ & & $83.9(82.2,85.5)$ & \\
\hline $4+$ & $70.0(68.6,71.3)$ & & $82.5(80.6,84.2)$ & \\
\hline \multicolumn{5}{|l|}{ Place of vaccination } \\
\hline Public health center & $86.2(85.8,86.7)$ & $71.25(0.000)$ & $86.2(85.6,86.8)$ & $8.80(0.000)$ \\
\hline Private health center & $82.6(80.9,84.2)$ & & $84.3(81.7,86.7)$ & \\
\hline \multicolumn{5}{|l|}{ Mother's age } \\
\hline $15-24$ & $82.0(81.3,82.8)$ & $85.20(0.000)$ & $86.3(85.4,87.2)$ & $5.96(0.051)$ \\
\hline $25-34$ & $80.7(80.0,81.3)$ & & $86.0(85.1,86.8)$ & \\
\hline $35+$ & $65.8(60.9,70.5)$ & & $78.7(71.0,84.7)$ & \\
\hline \multicolumn{5}{|l|}{ Mother's Education } \\
\hline No education & $71.4(70.4,72.4)$ & $1400(0.000)$ & $81.8(80.4,83.2)$ & $98.51(0.000)$ \\
\hline Primary & $79.9(78.6,81.2)$ & & $85.3(83.6,86.9)$ & \\
\hline Secondary & $84.7(83.9,85.5)$ & & $87.2(86.3,88.2)$ & \\
\hline Higher & $87.9(86.9,88.9)$ & & $88.8(86.8,89.1)$ & \\
\hline \multicolumn{5}{|l|}{ Media Exposure } \\
\hline No & $71.7(70.7,72.6)$ & $976.17(0.000)$ & $81.5(80.1,82.9)$ & $56.48(0.000)$ \\
\hline Yes & $84.4(83.8,85.0)$ & & $87.5(86.5,87.8)$ & \\
\hline \multicolumn{5}{|c|}{ Mother with 4+ ANC visit } \\
\hline No & $74.8(74.1,75.5)$ & $1400(0.000)$ & $83.1(82.1,84.0)$ & $95.97(0.000)$ \\
\hline Yes & $87.5(86.8,88.1)$ & & $88.6(87.8,89.3)$ & \\
\hline \multicolumn{5}{|l|}{ Place of residence } \\
\hline Urban & $83.3(82.1,84.3)$ & $70.81(0.000)$ & $86.1(84.7,87.3)$ & $0.03(0.854)$ \\
\hline Rural & $80.2(79.7,80.7)$ & & $86.0(85.4,86.7)$ & \\
\hline \multicolumn{5}{|l|}{ Religion } \\
\hline Hindu & $82.7(82.2,83.2)$ & $652.37(0.000)$ & $86.0(85.3,86.7)$ & $20.02(0.000)$ \\
\hline Muslim & $73.2(71.7,74.6)$ & & $84.9(83.2,86.5)$ & \\
\hline Others & $82.9(80.4,85.1)$ & & $89.6(87.3,91.6)$ & \\
\hline \multicolumn{5}{|l|}{ Social Group } \\
\hline Schedule Caste & $81.5(80.4,82.5)$ & $354.19(0.000)$ & $85.3(83.9,86.5)$ & $9.54(0.023)$ \\
\hline Schedule Tribe & $77.4(76.0,78.8)$ & & $87.1(85.4,88.7)$ & \\
\hline $\mathrm{OBC}$ & $81.0(80.3,81.7)$ & & $85.4(84.5,86.3)$ & \\
\hline Others & $82.4(81.3,83.5)$ & & $87.5(86.2,88.7)$ & \\
\hline \multicolumn{5}{|l|}{ Wealth Quintile } \\
\hline Poorest & $73.2(72.2,74.1)$ & $1200(0.000)$ & $82.8(81.4,84.1)$ & $62.68(0.000)$ \\
\hline
\end{tabular}


Appendix 1 Distribution of children who received MCV1 and those who received MCV1 at appropriate time by selected background characteristics in India, 2015-16 (Continued)

\begin{tabular}{llll}
\hline Variables & MCV1 Vaccination & & MCV1 at Recommended Age \\
\cline { 2 - 4 } & $\begin{array}{l}\text { Percentage } \\
(95 \% \mathrm{Cl})\end{array}$ & $\begin{array}{l}\text { Chi-square statistic } \\
(\boldsymbol{P} \text {-value })\end{array}$ & $\begin{array}{l}\text { Percentage } \\
(95 \% \mathrm{Cl})\end{array}$ \\
\hline Poorer & $78.8(77.8,79.8)$ & $85.9(84.7,87.1)$ \\
Middle & $83.1(81.9,84.1)$ & $86.0(84.6,87.4)$ \\
Richer & $85.7(84.5,86.8)$ & $88.0(86.6,89.2)$ \\
Richest & $88.9(87.6,90.1)$ & $87.4(85.9,88.7)$ \\
Place of Delivery & & \\
Institutional delivery & & $2000(0.000)$ & $86.6(85.9,87.2)$ \\
Delivered at home & $84.0(83.5,84.5)$ & & $82.5(80.7,84.1)$ \\
\hline
\end{tabular}

\section{Acknowledgements}

The authors express their gratitude to the reviewers and the editorial board of the Journal.

\section{Authors' contributions}

BKP and NA conceptualized the research; BKP designed the study, BKP and SM: analysis and interpretation of data; BKP, SM, NA: writing the first draft of the manuscripts, all the authors read and finalized the final version of the article. The authors read and approved the final manuscript.

\section{Funding}

We declare that we have not receive and funding for this work.

\section{Availability of data and materials}

We have provided details of data in methodology section. NFHS-4 data and survey tools can be obtained on request from International Institute for Population Sciences, Mumbai and DHS data register. The corresponding authors have the original data used for research purpose.

\section{Ethics approval and consent to participate}

As the survey is based on the secondary data and available in public domain, it needs no prior approval. But Informed consent were taken from all the respondents in times of surveys.

\section{Consent for publication}

Not Applicable.

\section{Competing interests}

Authors declared that they do not have any competing interest.

\section{Author details}

${ }^{1}$ International Institute for Population Sciences (IIPS), Mumbai, India. ${ }^{2}$ School of Health and Environmental Studies, Hamdan Bin Mohammed Smart University, Dubai, United Arab Emirates.

Received: 11 March 2020 Accepted: 30 July 2020

Published online: 10 August 2020

\section{References}

1. van den Ent MM, Brown DW, Hoekstra E, Christie A, Cochi SL. Measles mortality reduction contributes substantially to reduction of all cause mortality among children less than five years of age, 1990-2008. J Infect Dis. 2011;204(Suppl 1):S18-23.

2. Bogler $L$, Jantos N, Barnighausen T, Vollmer S. Estimating the effect of measles vaccination on child growth using $191 \mathrm{DHS}$ from 65 low- and middle-income countries. Vaccine. 2019;37(35):5073-88

3. Portnoy A, Jit M, Ferrari M, Hanson M, Brenzel L, Verguet S. Estimates of case-fatality ratios of measles in low-income and middle-income countries: a systematic review and modelling analysis. Lancet Glob Health. 2019;7(4):e472-81.

4. Organization WH. Organization WH: measles: factsheet. 2018; 2019.
5. Dabbagh A, Laws RL, Steulet C, Dumolard L, Mulders MN, Kretsinger K, et al. Progress toward regional measles elimination — worldwide, 2000-2017. Morb Mortal Wkly Rep. 2018;67(47):1323-9.

6. Ferrari MJ, Grais RF, Bharti N, Conlan AJ, Bjørnstad ON, Wolfson LJ, et al. The dynamics of measles in sub-Saharan Africa. Nature. 2008;451(7179):679.

7. Dabbagh A, Patel MK, Dumolard L, Gacic-Dobo M, Mulders MN, Okwo-Bele $J-M$, et al. Progress toward regional measles elimination - worldwide, 20002016. MMWR Morb Mortal Wkly Rep. 2017;66(42):1148.

8. Lessler J, Moss WJ, Lowther S, Cummings D. Maintaining high rates of measles immunization in Africa. Epidemiol Infect. 2011;139(7):1039-49.

9. Geremew TT, Gezie LD, Abejie AN. Geographical variation and associated factors of childhood measles vaccination in Ethiopia: a spatial and multilevel analysis. BMC Public Health. 2019;19(1):1194.

10. Kien VD, Van Minh H, Giang KB, Mai VQ, Tuan NT, Quam MB. Trends in childhood measles vaccination highlight socioeconomic inequalities in Vietnam. Int J Public Health. 2017:62(Suppl 1):41-9.

11. Lo NC, Hotez PJ. Public health and economic consequences of vaccine hesitancy for measles in the United States. JAMA Pediatr. 2017:171(9):887-92.

12. Sarkar S, Zlojutro A, Khan K, Gardner L. Measles resurgence in the USA: how international travel compounds vaccine resistance. Lancet Infect Dis. 2019;19(7):6846.

13. Suijkerbuijk AW, Woudenberg T, Hahne SJ, Nic Lochlainn L, de Melker HE, Ruijs WL, et al. Economic costs of measles outbreak in the Netherlands, 2013-2014. Emerg Infect Dis. 2015;21(11):2067-9.

14. Takahashi S, Metcalf CJE, Ferrari MJ, Tatem AJ, Lessler J. The geography of measles vaccination in the African Great Lakes region. Nat Commun. 2017:8:15585.

15. Wangchuk S, Nogareda F, Tshering N, Khandu L, Pelden S, Wannemuehler K, et al. Measles and rubella immunity in the population of Bhutan, 2017. Vaccine. 2019; 37(43):6463-9.

16. Mina MJ, Kula T, Leng Y, Li M, De Vries RD, Knip M, et al. Measles virus infection diminishes preexisting antibodies that offer protection from other pathogens. Science. 2019;366(6465):599-606..

17. de Vries RD, de Swart RL. Measles immune suppression: functional impairment or numbers game? PLoS Pathog. 2014;10(12):e1004482.

18. Hayman DT. Measles vaccination in an increasingly immunized and developed world. Human Vaccines Immunother. 2019;15(1):28-33..

19. International Institute of Population Sciences, ICF International. Natinal family health survey (NFHS-4), 2015-16: India. Mumbaihttp://rchiips.org/ NFHS/NFHS-4Reports/India.pdf: Government of India; 2017.

20. Faneye AO, Adeniji JA, Olusola BA, Motayo BO, Akintunde GB. Measles virus infection among vaccinated and unvaccinated children in Nigeria. Viral Immunol. 2015;28(6):304-8

21. Bose AS, Jafari H, Sosler S, Narula AP, Kulkarni VM, Ramamurty N, et al. Case based measles surveillance in Pune: evidence to guide current and future measles control and elimination efforts in India. PLoS One. 2014;9(10):e108786.

22. McKee A, Ferrari MJ, Shea K. Correlation between measles vaccine doses: implications for the maintenance of elimination. Epidemiol Infect. 2018; 146(4):468-75. 
23. Scobie HM, Ray A, Routray S, Bose A, Bahl S, Sosler S, et al. Cluster survey evaluation of a measles vaccination campaign in Jharkhand, India, 2012. PLoS One. 2015;10(5):e0127105.

24. Newtonraj A, Vincent A, Selvaraj K, Manikandan M. Status of coverage of MR vaccination, after supplementary immunization activities in a rural area of South India: a rapid immunization coverage survey. Rural Remote Health. 2019;19(3):5261.

25. Morris SK, Awasthi S, Kumar R, Shet A, Khera A, Nakhaee F, et al. Measles mortality in high and low burden districts of India: estimates from a nationally representative study of over 12,000 child deaths. Vaccine. 2013; 31(41):4655-61.

26. Wong BK, Fadel SA, Awasthi S, Khera A, Kumar R, Menon G, et al. The impact of measles immunization campaigns in India using a nationally representative sample of 27,000 child deaths. Elife. 2019;8:1.

27. MoHFW. Measles mortality reduction India strategic plan 2005 2010; 2004

28. Panda BK. Temporal trend and inequality in immunization coverage in India. In: Public health in developing countries-challenges and opportunities: IntechOpen; 2020.

29. Rammohan A, Awofeso N, Fernandez RC. Paternal education status significantly influences infants' measles vaccination uptake, independent of maternal education status. BMC Public Health. 2012;12:336.

30. Pramanik S, Muthusamy N, Gera R, Laxminarayan R. Vaccination coverage in India: a small area estimation approach. Vaccine. 2015;33(14):1731-8.

31. Singh A. Gender based within-household inequality in childhood immunization in India: changes over time and across regions. PLoS One. 2012;7(4):e35045

32. Khan J, Shil A, Prakash R. Exploring the spatial heterogeneity in different doses of vaccination coverage in India. PLoS One. 2018;13(11):e0207209.

33. Panda BK, Kumar G, Mishra S. Understanding the full-immunization gap in districts of India: a geospatial approach. Clinical Epidemiology and Global Health. 2020;8(2):536-43.

34. Awofeso N, Rammohan A, lqbal K. Age-appropriate vaccination against measles and DPT-3 in India-closing the gaps. BMC Public Health. 2013;13(1):358.

35. Brown DW, Gacic-Dobo M. Home-based record prevalence among children aged 12-23 months from 180 demographic and health surveys. Vaccine. 2015;33(22):2584-93.

36. StataCorp. Stata statistical software: release 15.[computer program]. College Station: StataCorp LLC, StataCorp LP; 2017

37. Kuhnt J, Vollmer S. Antenatal care services and its implications for vital and health outcomes of children: evidence from 193 surveys in 69 low-income and middle-income countries. BMJ Open. 2017;7(11):e017122.

38. Gupta R, Talukdar B. Frequency and timing of antenatal care visits and its impact on neonatal mortality in EAG states of India. J Neonatal Biol. 2017; 6(3):263.

39. Bawankule $R$, Singh A, Kumar K, Shetye $S$. Does measles vaccination reduce the risk of acute respiratory infection (ARI) and diarrhea in children: a multicountry study? PLoS One. 2017;12(1):e0169713.

40. Pandey S, Ranjan A, Singh CM, Kumar P, Ahmad S, Agrawal N. Sociodemographic determinants of childhood immunization coverage in rural population of Bhojpur district of Bihar, India. J Family Med Prim Care. 2019; 8(7):2484-9.

41. Stronegger WJ, Freidl W. A hierarchical analysis of social determinants of measles vaccination coverage in Austrian schoolchildren. Eur J Pub Health. 2010;20(3):354-9

\section{Publisher's Note}

Springer Nature remains neutral with regard to jurisdictional claims in published maps and institutional affiliations.

\section{Ready to submit your research? Choose BMC and benefit from:}

- fast, convenient online submission

- thorough peer review by experienced researchers in your field

- rapid publication on acceptance

- support for research data, including large and complex data types

- gold Open Access which fosters wider collaboration and increased citations

- maximum visibility for your research: over $100 \mathrm{M}$ website views per year

At BMC, research is always in progress.

Learn more biomedcentral.com/submissions 